\title{
The Comprehensive Meaning of Life in Bergson
}

\author{
Florence Caeymaex
}

Translated from the French by Edward F. McGushin ${ }^{1}$

There is good reason to consider Henri Bergson, alongside Nietzsche, Dilthey, and Simmel, as one of the major figures in the field of "philosophy of life." Bergson often evoked his very early interest in theories of evolution. ${ }^{2}$ As early as 1896, Matter and Memory - his book on the relation between the body and the soul-put in play the central role of the brain as the organ of "attention to life" in the activity of the mind, sketching a conception of the living body (corps vivant), i.e. of the body as a "center of action." But it is with the appearance of Creative Evolution - the work which established the national and international fame of Bergson from 1907 on (Azouvi 2007, 131) - that Bergsonism is definitively tied to the notion, or more exactly the image, of the "vital impetus" (l'élan vital). In both the mental and physical sense, it is the thematic of life that asserts itself as essential for all of Bergson's reflections. And it is to the evolution of life that this philosophy returns in 1932 in order to think through the problem of distinctively human sociability, that is to say, moral and religious phenomena.

In many respects, Bergson's philosophy is an attempt to renew metaphysics starting from biological science, which took off in the 19th century, and to found, on new bases, the alliance between science and philosophy that Descartes realized with mathematics. Just as Descartes had taken "mathematics as model and support," Bergson became a student of the life sciences, broadly understood (biological, psychological, sociological). He was not just looking for a modelthat of an empirical and experimental knowledge (connaissance)—but he also had the aim of elaborating a properly metaphysical signification of the notion of life, born of a philosophical intuition conceived as a direct vision of the real. 
And yet, despite the link that deeply unites philosophical intuition and life, Bergson's theory of life is not vitalism, as it is sometimes thought to be. And this for two reasons: on the one hand, because life is not the sole problem dealt with in Bergson's philosophy, and on the other hand, because this philosophy never postulates a "vital principle" at the core of reality. First of all, we will recall that, in effect, Bergson presented each of his great books as an "entirely new effort" to treat a new problem (Bergson 2009b, 97). Hence, the "true nature of life" is neither given nor presupposed in Matter and Memory, and Creative Evolution does not hold all of the keys to the moral problem treated in The Two Sources of Morality and Religion. Moreover, while Bergson really did seek to isolate the metaphysical sense of life, starting from the sciences of life (physical, organic, social), and while he developed this meaning across his different works, he never advanced "life" or "vitalism" as the ultimate, unique, or all-encompassing explanatory principle. The continuity of Bergson's œuvre is foreign to any systematizing spirit, to any will "to take hold of the whole of knowledge virtually in a single principle" (Bergson 2009b, 27).

Therefore, we need to understand that while a philosophy of life really is elaborated in Bergson's works, life is neither a "principle," nor a privileged site of philosophical intuition. The attempt to integrate the science of life with metaphysics leads not only to the elaboration of a theory of life, but to the complete revision of metaphysics, that is to say, to a profound transformation of philosophical thought or intelligibility itself. The primary notion, the one that fully expresses this transformation, is not that of "life," but rather that of "duration" (la durée).

"Duration" has a double sense for Bergson: an ontological sense-it refers to the intuition that the essence of reality is becoming - which is inseparable from a gnoseological or theoretical sense-referring back to the idea that an absolute knowledge or knowledge of the absolute is a "thinking in duration." This notion constitutes neither the center nor the principle, but rather the obligatory point of passage for all the problems treated by Bergson. For this reason, we should say that it is possible to seize "the true nature of life" starting from duration, but life is not "le tout" of duration. But as we will see, the intuition of duration is born from a certain experience of life and it gives back to "life" the comprehensive meaning that Bergson attributes to it.

Creative Evolution is situated at the heart of this complex problematic. In effect, one finds in this book the elaboration of a theory of life, which, by following the trail of facts isolated by scientific knowledge, arrives at the necessity of a new genre of knowledge. It is also the realization of the limits of our ordinary 
intellectual categories, which are incapable of grasping the essence, or more exactly, the whole, of life. This is the reason why the theory of life is inseparable from a critique and theory of knowledge, through which Bergson will be led to specify how science and metaphysics are different and yet complementary, thus demonstrating the respective roles of intelligence and intuition. By remaining at the level of life itself we will be able to explain why our intelligence, which always remains a vital function, naturally tends to misapprehend life and incites, because of this very fact, an intuition which will surpass it.

The aim of this book is to grasp what Bergson calls "the true nature" of life, or more exactly, "the profound meaning of the evolutionary process" (Bergson $2007 \mathrm{~b}, \mathrm{vi}$ ). Bergson situates his reflection in relation to the sciences, which take living beings as their object; to the extent that the idea of evolution has become their common presupposition, it is, for him, the obligatory point of departure for any theory about the essence of life. The way one conceptualizes the nature of life-and hence its relations with brute, inorganic matter-is strictly dependent upon the way one conceptualizes the evolutionary process.

On the basis of the first and second chapters of Creative Evolution, this essay attempts to outline the essence of Bergson's theory of life in relation to his theory of knowledge and his metaphysics. My intention here is not to provide a summary of all the implications of this theory of life, ${ }^{5}$ but rather to offer, departing from this determinate thematic, some of the keys to his work as a whole.

\section{Living body and duration}

In the first chapter of the book, Bergson shows that evolutionary theories generally content themselves with applying traditional notions of finality or mechanism, and this, despite the empirical indications provided by the sciences themselves. Having indicated the inadequacy of traditional notions for comprehending the simple existence of the organized or living body, Bergson goes on to show why they are a fortiori worthless for understanding the evolution of life. This is how he is led to propose the image of the vital impulse for thinking evolution, which, on the one hand, breaks with the mechanistic perspective, and on the other, profoundly transforms the teleological perspective.

The line of questioning that opens the chapter actually bears on the modes of existence of entities, and Bergson begins by recalling the results of his previous works. For him it is established that our existence, as we perceive it from the inside or psychologically, is-to speak in absolute terms-uninterrupted 
qualitative change, a reality with the defining characteristic of enduring (durer), of persisting through change, of bringing about an irreversible transformation. It is equally established that the material objects of our external perception exhibit the "inverse character" (Bergson 2007b, 7). Our perception fragments material reality into discontinuous parts and attributes change to a modification of the order and quantity of the parts. Science takes up the stance of perception: the succession that it observes, the causality that it postulates (and that it translates into the language of mathematics), reduced to a quantitative change, assumes the character of a reversible time, similar to that of a videotape that one could play backwards in order to return to the first image or to the initial conditions. The mechanical causality of physics is not an absolute negation of time, but rather rests on a concept of time arrived at by abstraction from the real duration. The reversible time of physics is, for Bergson, an artifice designed to conceptualize the set of changes possible in a system. In this perspective, time is not active; it does nothing: "the present contains nothing more than the past, and whatever one finds in the effect was already there in the cause" (Bergson 2007b, 14).

Between the psychological and the material, where should one situate the living body? If it is incontestably a portion of material extension, subject to physical and chemical laws, then it is more than a simple assemblage of parts or points of matter. One cannot adequately describe it by means of categories applicable to the raw material objects that sense-perception and the physical sciences target. Organic unity, on the one hand, tends toward a "certain systematization of parts"6 (Bergson 2007b, 14); on the other hand, this unity is primarily the continuity of a "thing which endures (dure)," a being whose past "persists in its entirety in its present, remaining actual and active" (Bergson 2007b, 15). The most evident manifestation of this duration, of this persistence through change in the living being, "the register in which time itself inscribes itself" (Bergson 2007b, 16), is the irreversible process of aging. For Bergson, there is no fundamental difference between embryonic development and aging: it is a matter of one single continuous process, which is the "perpetual change of form" (Bergson 2007b, 18). ${ }^{7}$ Therefore, in a certain sense, there is, in aging itself, the production of novelty, what Bergson names "creation." One should understand by this not a process of fabrication, the production of an object, but rather a transformation, the becoming-other of the organism. In this becoming, the present state encompasses and includes the whole set of past states-one could speak of an organic memory - but without having been given, that is to say, without having been contained in the preceding states as a possibility ${ }^{8}$ : it is more than and other than simply the series of preceding states added together; it is the 
set of these past states modified. Bergson had already encountered this concrete duration in his preceding works: in Time and Free Will and then in Matter and Memory duration defined the essence of psychic and psychological phenomena. It appeared in those works as the essential difference between the living and the dead, the organic and the inorganic. The fundamental characteristic of the organized body is becoming or history: a continuity where the past acts as a memory coalescing with the present (Bergson 2007b, 22) and the creation of something novel and previously unforeseeable.

Embryology, histology, theories of heredity—so many domains of knowledge in which becoming plays an essential role. For Bergson, the direction taken by the biological sciences of his time, by making duration appear as a reality, put the received conceptual frameworks of the material sciences to the test-conceptual frameworks which substitute abstract time for concrete duration. It calls for another model of intelligibility, if not in the biological sciences themselves, then at least at the level of a theory of life.

In my view, it is not a matter of disqualifying the physico-chemical approach to organic phenomena, but of showing that in order to elaborate a theory of life one must depart from the (legitimate) path of physico-chemistry. In sum, to think organization is to break with Cartesian mechanism. But it is also to break with the teleology that has typically been seen as the alternative to mechanism. This is what orients Bergson's opposition to vitalism, which, against mechanistic reductionism, attempts to explain the organization of living beings as a function of a "vital principle." These theories, which one finds among certain well-known biologists of the time, ${ }^{9}$ hold that the development of organisms obeys an internal principle, independent of physico-chemical causality, acting within each individual as a final cause and making it take such and such a form of organization. ${ }^{10}$ When all is said and done, if the mechanistic view sees the whole course of development already determined by the initial conditions, a teleological view inscribes it in the future; in either hypothesis, duration or real evolution counts for nothing because one presupposes that "all is given" (Bergson 2007b, 39).

\section{Evolution and vital impetus}

If mechanism and teleology are incapable of accounting for the evolutionary process characteristic of living beings and organized bodies, what will happen when one applies them to evolution at the level of life as a whole? Beginning 
with Lamarck, the idea slowly took hold that the relationships and differences established by the classifications of natural history had to be thought according to a temporal order or chronological succession, leading to what Bergson calls "transformism" (Bergson 2007b, 23-4). This lets us see, at the level of the totality of living beings, a series of continuous transformations that, branching off along different paths, give birth to new species, and also to new individuals that in themselves represent an original variation of the species. On a grand scale, it is a process of creating unforeseeable forms. Bergson admits that transformism, or the theory of evolution, remains a hypothesis that cannot be demonstrated. But this is not a fatal objection because it underscores that, on the one hand, the rich development of the life-sciences confers on this hypothesis an "indefinitely increasing probability" (Bergson 2007b, 24) and, on the other hand, that evolutionism has already acquired the status of what we would today call a "paradigm" for the biological sciences. ${ }^{11}$ Under these conditions, how could a mechanistic conception-the logic of which is essentially predictive and thus focused on the repetition of the same-presume to hold the key to a philosophy or theory of life? Similarly, under these conditions, how could a radical teleology - which conceives of creation as production according to a goal, plan, or model—continue to have meaning?

In rejecting mechanism and radical teleology Bergson is taking a philosophical position, but that position is not the result of reflecting on principles. His challenge to them comes about through a kind of crucial experience, over the course of which a series of concurrent scientific hypotheses will reveal the limits of mechanistic reasoning ${ }^{12}$ as well as the need for a different understanding of teleology.

This crucial experience involves the question of how the eye develops over the course of evolution. How must one comprehend the process that led to the existence of such a marvelously complex structure ${ }^{13}$ And especially, how can we account for the fact that one finds analogous structures along different evolutionary lines (e.g. the human eye and the eye of certain mollusks), as if nature had opted for certain determinate organic structures, rather than for chaos? Bergson's argument shows that, when faced with these questions, all of the mechanistic theories of evolution are invalidated: either they give up the attempt to explain the directions of evolution-and, therefore, of organization itself-or they surreptitiously reintroduce a final cause which explains the directions taken by evolution. ${ }^{14}$ This is the kernel of truth contained in the scientific hypotheses: it does not seem possible to rely on a certain teleology to understand evolution, and yet a theory of life must be able to affirm at the same time both that evolution 
is an unpredictable, "continual creation of forms" (Bergson 2007b, 87) and that it is not, for all that, completely arbitrary.

Each of the scientific hypotheses gives only a partial view of evolution (Bergson 2007b, 85). It is up to philosophy to disengage, at the intersection of the "trail of facts" traced by the sciences, the ideas that they suggest about the subject of life. This idea will not have the transparency of a concept because it takes form at the moment when we let go of our ordinary intellectual categories and swim against the mechanistic current proper to scientific conceptualization. In effect, this is why the idea of life is given by way of an image, the image itself translating the intuition that lies at its source.

Before making explicit what the image chosen by Bergson designates, let us note what he wants to retain from the scientific hypotheses, the elements that he takes to be partial "points of view" on truth (Bergson 2007b, 86-8). From neo-Darwinism ${ }^{15}$ (the theory of mutations), he holds on to the idea of a tendency toward internal change, independent of the behavior of the individual; from the hypothesis of orthogenesis, ${ }^{16}$ that variations proceed from generation to generation in a definite direction; from neo-Lamarckism, ${ }^{17}$ the idea that the directions taken by evolution follow from a nonsubjective, nonindividual psychological causality: from a movement similar to an effort, that is, to an impulse or a will reaching toward the future (François 2008, 55). ${ }^{18}$

The image of the vital impetus translates these different aspects of evolutionary development and the organization proper to life. In this image, life appears as a "current" flowing from an original common impulse and which, in moving forward, branches into divergent evolutionary lines (Bergson 2007b, 53) - along which the distinct forms of life, species, and even different individuals are distributed. If you do not accept the hypothesis of radical teleology, how do you account for these divergences, which are organized in these directions? Even when divided, this impetus is no less continuous along those lines where it becomes actual through the accumulation of variations and differences, in the manner of a consciousness wherein the past remains active in the present. The structural similarities that one finds among these distinct lines arises from the fact that all the evolutionary lines have a common origin (Bergson 2007b, 51), as if the latter contained the virtualities (Bergson 2007b, 182) or the tendencies (Bergson 2007b, 51-3) induced to fulfill themselves through a labor of invention and creation. These virtualities are neither spatial forms of organization nor the structures of living beings, but first of all the virtuality of functions. Hence the formation of the eye over the course of evolution could be understood as the result of a "progress of vision" 
(Bergson 2007b, 97). Its similarity in very different species simply expresses the acquisition by life, in each of its forms, of one and the same power of vision.

With the image of impetus Bergson is on his way toward assimilating the vital impetus with the stream of consciousness and toward the idea of a properly psychological, though nonsubjective and nonindividual, causality at work in life. First, the vital impetus manifests all the characteristics of the duration proper to psychological existence: unpredictable development, continuous change, qualitative transformation, and irreversible becoming, which is ance both conservation and creation. Second, the division of impetus into divergent directions amounts to the many "choices" (Bergson 2007b, 97) by which the intentions of life - that is to say, the virtualities of impetus-are realized, without these intentions ever requiring the representation of a goal to attain. ${ }^{19}$ Finally, saying that the virtualities or internal tendencies of impetus are virtualities of function serves to underscore that life is essentially action in the strong sense of the term, a free activity, which implies an act of consciousness to some degree. In sum, should we say that what is properly vital in life is consciousness (Bergson 2007b, 182-3)? At a conference in Birmingham in 1911, ${ }^{20}$ Bergson confirms that the relation between life and consciousness is not only one of analogy. He claims that "de jure if not de facto, consciousness is coextensive with life" (Bergson 2007b, 180 and 2009a, 13).

\section{Organization: Life and materiality}

Though the vital impetus is a stream of consciousness, life does not express itself any less by its activity of material organization. We have seen that living bodies distinguish themselves from inert material bodies by their organization-that is to say, by a continuity of duration. It is now evolution itself which could be understood as a work of organization, in such a way that the nature of the relationship between consciousness and materiality, constitutive of life, becomes clearer. This point should allow us to specify the kind of relationship that exists in the living being between the function and the system that performs it.

On all of these points, the labor of organization distinguishes itself from fabrication, because the latter is precisely not a creation- "the artisan," says Bergson, "discovers in his product only what he puts in it" (Bergson 2007b, 93). Vital organization is something other than the assembly of means with a view to some end, something other than the arrangement of material elements according to a plan. The act of organization is, in fact, a simple one, which is 
accomplished when impulse, like an explosive discharge of energy (Bergson 2007b, 99), encounters matter and seeks to cut a path through it. The resistance of matter makes it both the instrument and the obstacle that divides and clarifies impetus (élan) (Bergson 2008, 118), in such a way that impetus (élan) must actualize its virtualities in an original way. From this perspective, the material organization of the living body-but also, at another level, the organ, or any living element whatever it may be-manifests itself as the contingent effect achieved by impulsion when it successfully breaks through or "outflanks" the obstacle of matter. The materiality of the living body or the organ "no longer represents an ensemble of means employed, but rather an ensemble of obstacles that have been outmaneuvered" (Bergson 2007b, 94). If one can speak of an adaptation of life to external conditions, it is not in the sense that these conditions would be the cause of organic forms-either by direct or indirect actions-but in the inverse sense, where adaptation translates "the original solution, found by life, to the problem which the external conditions posed" (Bergson 2008, 117).

We have said that the original impulsion includes these virtualities of functions, that is to say of action, and that the resistance of matter divides and clarifies this impulsion. Everything happens as if the organic function-seeing, that is, capturing light-were this virtuality made actual, active, or effective thanks to the narrowing, to the "canalization" of this power of seeing imposed by matter's inertia. From this point of view, the organ is not the instrument of the function, born of an accidental assembly or guided by more or less complex material structures. The organ, the instrument, is less than all that: "the visual apparatus simply symbolizes the work of canalization" (95), a partial view taken on a simple and indivisible act, the "progress of vision." ${ }^{11}$

\section{Metaphysical import of the image of vital impetus: The meaning of life}

In a single phrase, Bergson summarizes the two aspects depicted in the image of vital impetus (consciousness and organization): "Everything happens as if a large current of consciousness - charged like all consciousness with an enormous multiplicity of interwoven virtualities - had penetrated into matter. It organized matter, but its movement was simultaneously slowed down and split up by it" (Bergson 2007b, 182).

The perspective on the evolutionary process that Bergson develops in the second chapter of Creative Evolution is a continuation of this image. This 
process is not a linear progress toward complexity (Bergson 2007b, 136). It is an act which, under the pressure of matter, diffracts itself into a multiplicity of life-forms. Such a multiplicity is nevertheless channeled into three principle directions along divergent lines which Bergson understands as so many different actualizations of a single tendency to act on brute matter (Bergson 2007b, 97). ${ }^{22}$ The focus bears less on the material forms of living beings than on the distinct modalities by which the operation of life realizes itself, that is to say, in essence, the eruption of consciousness. This is the reason why Bergson first distinguishes, in the world of living beings, between the nearly unconscious "torpor" of vegetal life and the vivacity of animal life. And second, among animal species, between the quasi-automatism of instinct and the free operation of intelligence (in the great vertebrates and human beings). From this point of view, human intelligence marks the highest achievement of the vital impetus, as if, at this level, life becomes more supple, dynamic, and conscious.

These considerations could have an impact on the biological sciences, but the real stakes of the image of the vital impetus are primarily theoretical and metaphysical; they overturn the philosophical tradition on at least four points. ${ }^{23}$

By refusing to comprehend evolution according to the model of "fabrication," the image of the vital impetus neutralizes the model of intelligibility common to mechanism, classical finalism, and ordinary, practical intelligence. In effect, it inverts the perspective, deeply rooted in human intelligence, which leads us to impute positivity to matter and negativity to consciousness or to duration. Here, negativity is on the side of matter, which represents the diminution of the positive nature of the impetus (Bergson 2007b, 211). ${ }^{24}$ The positive element in the living being is its duration: its becoming, its evolution.

For all that, Bergson does not reinstate a substance dualism. ${ }^{25}$ The image of the vital impetus implies solidarity between impetus and resistance. This solidarity is essential to vital creativity, to the extent that life singularizes itself by an internal duality of tendencies. Here, philosophy introduces the fundamental theme of the finitude constitutive of life (Bergson 2007b, 254). We experience this finitude in the feeling of effort, that is to say, by way of the resistance that we oppose to the resistance of matter. ${ }^{26}$

On several occasions we have spoken of the "virtualities" of impetus. Bergson uses the term often in order to qualify the source of the directions or tendencies present in the life's evolution, without relying on a traditional teleological model. The creation proper to the vital movement is therefore never ex nihilo: it implies virtualities. As Deleuze has stressed, the "virtual" must be carefully distinguished from the "possible," as conceived according to traditional metaphysics and 
enveloped in the model of fabrication. ${ }^{27}$ Reality is not the actualization of a possibility, the realization of a plan through reproducing it. It is rather a multiplicity of virtualities of which the actualization requires not only an effort of creation or invention, but also a reduction (rétrécissement) or a choice. In this way, actualization obeys a regime of differentiation completely different from the regime of duplication, which in classical metaphysics articulates the real and the possible ${ }^{28}$ : in this way the evolution of life advances toward vision, but under different forms, "in species which have totally different histories" (Bergson 2007b, 87).

Finally, we must understand that in the Bergsonian perspective life no longer has the status of a general concept under which the totality of living beings will be grouped: "we must no longer speak of life in general as an abstraction, or as a simple rubric under which one inscribes all living beings" (Bergson 2007b, 26). Moreover, life is not a "principle" at the foundation of all living beings. Rather life is, in general, more aptly described as a "tendency to act on brute matter" (Bergson 2007b, 97). Its mode of action, however, is not predetermined. Understood in terms of evolution and the image of impetus, it is first of all "the ensemble of a very long history" (Bergson 2007b, 20), "a single, indivisible history" (Bergson 2007b, 37) - each evolutionary path, each species, and each individual life traces its own singular, unique history inscribed in the history initiated by the original impetus. The historicity of life, and similarly the historicity proper to each individual living being - that is to say, its pace as a singular, irreversible, creative and finite process-only appears when one forces oneself to think "in duration." This thinking in duration adopts an inverse approach to the reasoning mobilized by traditional metaphysics, since the latter proceeds, like science, through generalization and categorization. Constructing a theory of life does not mean, as we have seen, neglecting the "lines of evidence" established by the biological sciences, but adopting toward them a comprehensive method which would not make time an abstraction. Therefore, the theory of life aims to grasp "genuine nature" (vraie nature): the latter is not an essence fixed in place by a concept, but the totality opened by a history that the image of the vital impetus expresses.

\section{Intelligence and intuition}

Bergson's theory of life is bound up with some firmly held metaphysical positions, but it is far from dogmatic. The rejection of traditional metaphysics-forever too 
Platonic - in effect gathers its arguments from a knowledge (connaissance) which circumscribes the exercise of the mental faculties (facultés de l'esprit) according to their direction and their domain of application (Bergson 2007b, 179). Two traits distinguish this critique: first of all, it is not, as with Kant, tied to a priori reflection, but to an experience; ${ }^{29}$ second, it offers philosophy, or metaphysics, the possibility of a new use of scientific, and in particular biological, knowledge.

Bergson's theory of the faculties deals first with intelligence. As we have seen, the latter is one modality of life's functioning that has arisen over the course of evolution. As with instinct, it is constitutively ordered toward action. But instinct is an immediate knowledge of its object and immanent to action itself, "sculpted to fit life," so to speak. Intelligence, however, proceeds in a mediate or indirect way, in order to know and get a hold on reality. In effect, Bergson defines intelligence as a faculty "for fabricating unorganized instruments, that is to say, artifacts" (Bergson 2007b, 151), a faculty by which the intelligent being acts on matter. Its object is, first of all, the "unorganized solid." Fabrication requires a specific, somewhat formal, externally oriented type of knowledge, which consists in representing relations (Bergson 2007b, 152) between discontinuous elements: a knowledge that envisions reality in terms of space, that is to say, in terms of a "homogenous and empty, infinite and infinitely divisible milieu completely open to any mode of decomposition whatsoever" (Bergson 2007b, 157). Indifferent to duration, novelty, and radical becoming, intelligence "is characterized by a natural incomprehension of life" (Bergson 2007b, 164). It is constituted in such a way that it comprehends inert matter, and anything in any way explicable, as a combination of unorganized solids.

Therefore, the mechanistic outlook roots itself in the operations of an intelligence focused on production all the while attempting to apply itself little by little to the whole of reality. The strength of formal knowledge lies in its capacity to reach every object, including those beyond the range of action (Bergson 2007b, 152). When it distances itself from its practical interest, intelligence is bound by its nature to want to reconstruct the whole of reality as a system regulated according to principles or laws, elaborating general concepts from elementary representations. This is the source of the tendency that led human knowledge to the physical sciences and then to a theory of matter, which in many ways served to confirm the most ancient metaphysics, itself based on intellectualism. But how could any metaphysics aiming to encompass the whole, or the essence, of reality be established on intellectualism, which precisely has the task of abstracting, that is to say of considering reality only from an established point of view, outside of any duration? 
Bergson's theory of knowledge sets out a double critique: a critique of intelligence and science that circumscribes and measures their reach; and a critique of traditional metaphysics that radically inverts its direction. Although sufficient for the domain of action and the scientific study of inert matter, intelligence reveals its limits, its "maladaptation" (Bergson 2007b, 165), as soon as it has to deal with the life of the body or the mind, organic or spiritual life, that is, with living beings. For Bergson, it is not a matter of refuting the legitimacy of an intellectual approach to organic phenomena, ${ }^{30}$ but of suspending it when it is time to grasp "the true nature of life," in other words what is properly "vital" in living beings.

In this case, the philosopher will have to take a different (inverse) tack than that of intellectualism, which decomposes, abstracts, spatializes, and reconstructs in order to explain. The philosopher will have to become reacquainted with that which disconcerts the intellect but which is, nevertheless, the very heart of life: duration. Bergson designates the effort that goes against the grain of intellectualism ${ }^{31}$ with the name "intuition." It recovers something of the instinct by which activity continues the labor of vital organization without rupture: ${ }^{32}$ an agreement, indeed, a coincidence with life. Intuition would be like instinct "having become disinterested, conscious of itself" (Bergson 2007b, 178). It is not the pure negation of intellectualism, but a comprehensive movement of enlargement, by which the mind (l'esprit) reunites with the life from which it derives its own impetus-and with the evolution in which the direction and limits of intelligence are rooted.

But what is at stake in intuition goes well beyond a theory of life. For the intuition of life is in essence an active hold on duration in the experience of life, the whole metaphysical weight of which, its status as absolute reality, Bergson put forward as early as Matter and Memory (Bergson 2007b, 338-9 and Bergson 2010, 232-3). The "comprehension in duration" of intuition can, in effect, expand to matter itself, which finds its place in the infinite plurality of "rhythms" or "tensions" of duration (Bergson 2009b, 95). In this way, intuition as the experience of duration is the point of departure for a philosophical act that breaks with traditional metaphysics. ${ }^{33}$

In fact, it is by an act of intuition that "life" (Bergson sometimes says, "the biological") acquires its profound significance, or more precisely the "very comprehensive" meaning that scientific explication foresees but cannot reach. Traced back to duration, the notion of "life" can integrate the different dimensions that ordinary language spontaneously gives to it when speaking about organic life, psychic life, or social life. 
But coming to an end, we have to add that the philosophical act would never reach the absolute if it were not the continuation or integration of multiple experiences we have of life, within us and outside of us.

Intuition would thrust us into consciousness in general. But is it only with other consciousnesses that we sympathize? If every living being is born, grows, and dies, if life is an evolution and if duration is here a reality, is there not also an intuition of the vital and, consequently, a metaphysics of life that will extend the science of the living? . . the fundamental cause of organization ... do we not reach it by recapturing through consciousness the impetus of life that is within us? (Bergson 1934, 28)

For it is in the most intense experiences of life, those that break the frameworks of our categories and intellectual habits, that we come back in contact with creative duration: the free act, emotion, artistic creation, and moral creativity (la création moral). ${ }^{34}$ If the notion of duration is the crossroads of all the problems taken up in Bergson's metaphysics, it is, nevertheless, starting from our experience of living beings that we are able to grasp its scope and meaning.

\section{Notes}

1 The translator would like to thank Christian Martin for his invaluable assistance and Scott Campbell for reading drafts line by line to make this a much better translation.

2 In particular for the work of Herbert Spencer (1820-1903), who was committed to a mechanistic view of the world and who attempted to elaborate an evolutionary theory that could serve as the basis for defining the "principles" of psychology, biology, sociology, and ethics. Though he held on to Spencer's idea of a knowledge "modeled on the details of the facts," Bergson nevertheless vigorously rejected what he quickly came to think of as a "false evolutionism" (Bergson 2009b, 2 and Bergson 2007b, x, 363-9).

3 "Psycho-physical parallelism and positive metaphysics," discussion at the Société française de philosophie, May 2, 1901 (Bergson 2011, 259).

4 See La pensée et le mouvant: Introduction, Deuxième partie. De la position des problemes. Each work offers to those that follow certain results, but each is organized around a different problem and constitutes an entirely new creation.

5 Notably its implications for anthropology and practical philosophy, which we take to be very important (Caeymaex 2012, 311-33).

6 This very important and original thesis links living (la vivant) to a process of individuation and not to strict individuality - which is "never perfect" according to Bergson (Bergson 2007b, 14). 
7 Perhaps it is not possible to establish a rigorous distinction in organic life between the creative and destructive processes. This distinction has an essentially quantitative sense, signifying growth and diminution respectively. Bergson substitutes for this view that of a qualitative change (change of form), where creation means at once continuity and change.

8 For the critique of the notion of the "possible," see notes 24 and 25 below, as well as (Bergson 2009b, 99-116) ("Le possible et le reel”).

9 Doctrines called "neo-vitalist" that postulate, alongside mechanistic processes, an independent vital principle: the "entelechies" of biologist and philosopher Hans Dreisch (1867-1941); the "dominants" of botanist, theist, and reactionary Reinke (1848-1931).

10 In addition to the indeterminacy of the notion of the vital principle, which by itself does not explain anything, this thesis of Aristotelian ancestry is inconsistent, like every theory that wants to make finality a principle internal to the individual. At what level will we effectively situate individuality: the organized body, the organ, or the cell? Bergson's idea is that if life is organization in the sense that it tends to produce systems, it is impossible to designate a sole organic entity as "individual," absolutely speaking. The cell itself is already "organized" and forms an organization with other cells. In these conditions, where individuality is never "perfect," there could be no "internal" finality (Bergson 2007b, 14 and 42-3).

11 "We suspect that the language of transformism now imposes itself on every philosophy, just as the dogmatic affirmation of transformism imposes itself on science" (Bergson 2007b, 26).

12 In the critical sense of the term. For Bergson it is not a matter of denying the legitimacy of a methodologically mechanistic approach to organic phenomena by the physico-chemical sciences, but of defining the field of application for this approach. It will become clear that another approach altogether will be necessary to comprehend "the whole" of life.

13 See (Bergson 2007b, 61-3).

14 The theory of "accidental variations," whether they be gradual or abrupt, whether or not they rely on an environmental selection (or adaptation) to take place, do not explain how the variations are maintained and add up in such a way that they produce the eye as an effect; It [i.e. the theory of accidental variations] does not explain either how such different causal series could result in similar or analogous effects, except by bringing in, implicitly, the genie of species which secures the arrangement. The same holds for the idea that the variations could be the direct effect of external conditions: must one say that the formation of the eye-an organ adapted to use light-is caused by the action of light? Obviously not. In fact one admits that organic matter possesses a "sui generis capacity" for "building machines ... for taking advantage of the simple excitation the influence of which it receives:" another name for the final cause. 
15 Hugo De Vries (1848-1935), Dutch botanist, cytologist, and hybridist, attempted to explain variations in species by the phenomena of "mutation" through the hereditary transmission of "pangenes" at the cellular level.

16 Theodor Eimer (1843-98), zoologist, countered the Darwinian idea of random variation with the idea of a variation operating in a determined direction (the idea of orthogenesis), resting on a physico-chemical causality.

17 Bergson, despite his vigorous opposition to the idea of heredity of acquisitions (l'acquis), nevertheless referred to the doctrine of Edward D. Cope (1840-97), known for his work in paleontology and embryology, who in a novel way countered the Darwinian theory of natural selection and understood evolution from an "energetic" perspective (clearly the point which influenced Bergson).

18 The notion of impetus refers back to the dimensions of time or the duration of a consciousness. If impetus looks like a will, it is so insofar as consciousness tends toward the future (François 2008, 55-71).

19 Bergson explicitly uses this experience in The Two Sources of Morality and Religion, in a key passage where, in order to clarify them, he returns to the ideas that he intended to convey via the image of the vital impetus (Bergson 2008, 115-20). He specifies, and this is very important, that one must not give an anthropomorphic sense to this notion of intention, because intention here is not at all the representation of a goal to attain, but rather a virtuality implicit in the original impetus. We could add that Bergson emptied this term, like that of consciousness, of all subjectivist signification.

20 The lecture is entitled "La conscience et la vie" (Henri Bergson 2009a, 1-28). The analogy is not immediate and assumes a detour through the external world (Riquier 2009, 388-93).

21 Bergson elaborated this idea with respect to the subject of perception in Matter and Memory, which he explicitly refers to in Creative Evolution (Bergson 2007b, 94): vision would be "a power which would accomplish, rightfully, an infinity of things.... But such a vision would not last in action.... The vision of a living being is an effective vision, limited to the objects upon which the being can act: it is a canalized vision...."

22 These three modalities of life are contained in the initial impulsion as virtualities, and their development comes about in the form of a dissociation: "Vegetative torpor, instinct, and intelligence, in sum elements which coincided in the vital impulsion common to plants and animals, and which, over the course of a development where they came forward in the most unexpected forms, broke away from each other by the sole fact of their growth (croissance)" (Bergson 2007b, 135-6).

23 These are fundamental themes that one discovers in the later writings where Bergson specifies the nature of his metaphysical project, notably in the double introduction to La pensée et le mouvant. 
24 Bergson is a thinker of dualities, but not a dualist.

25 On this point, as well as on the status of the negative in Bergson, see (Jankélévitch 1959) (Caeymaex 2008, 629-40) and (Caeymaex 2010, 261-83).

26 See (Bergson 2009b, 99-116) and (Deleuze 1966, 99-103).

27 See (Bergson 2009b, 5 sq. and 19). Here "comprehending" means expanding the habitual logic of our thinking in the direction of duration.

28 In the Introduction to Metaphysics, Bergson shows that his method does not proceed by way of generalization but rather by way of integration and that metaphysics can be understood as "integral experience" (Bergson 2009b, 227).

29 Bergson admits in effect that the physico-chemical approach to organic phenomena finds its verification in the analysis of the functional activity of the living being (Bergson 2007b, 36).

30 Which is a torsion of intelligence on itself (Bergson 2007b, 162).

31 "Because it only continues the work through which life organizes matter, to such an extent that we could not say ... where the organization ends and where instincts begins. When the little chick breaks its shell with one peck from its beak, it acts instinctively, even though it only follows the impetus which propelled it during its embryonic life" (Bergson 2007b, 166).

32 As Fr. Worms wrote, intuition is "the apprehension of the meaning of life of which human intelligence is the concrete incarnation" (Worms 2004, 224).

33 We have already noted some elements of this critique of metaphysics. This is also what is at stake in the final chapter of Creative Evolution.

34 These three vital experiences are clearly privileged by Bergson as inferior or superior intuitions akin to philosophical intuition. Free act, artistic creation, and emotion are thematized throughout Bergson's work. In The Two Sources, mystical intuition comes forward as the most intense intuition, the one which culminates in the highest form of creation: moral creation (the creation of moral sentiments).

\section{Bibliography}

Azouvi, François. (2007), La gloire de Bergson. Essai sur le magistère philosophique. Paris: Gallimard.

Bergson, Henri. (2007a), Essai sur les données immédiates de la conscience. Paris: Presses Universitaires de France. Originally published 1889.

—. (2007b), L'évolution créatrice. Paris: Presses Universitaires de France. Originally published 1907.

-. (2008), Les deux sources de la morale et de la religion. Paris: Presses Universitaires de France. Originally published 1932.

—. (2009a), L'énergie spirituelle. Paris: Presses Universitaires de France. Originally published 1919. 
-. (2009b), La pensée et le mouvant. Paris: Presses Universitaires de France. Originally published 1934.

-. (2010), Matière et mémoire. Paris: Presses Universitaires de France. Originally published 1896.

- (2011), Ecrits philosophiques. Paris: Presses Universitaires de France.

Caeymaex, Florence. (2008), "Négativité et finitude de lélan vital," in Annales bergsoniennes IV, Paris: Presses Universitaires de France, 629-40.

-. (2010), "Lanalyse des idées d'existence et de néant," in A. François (ed.), L'évolution créatrice de Bergson. Paris: Vrin, 261-83.

-. (2012), "La société sortie des mains de la nature. Nature et biologie dans Les deux sources," in Fr. Worms et al. (eds), Annales bergsoniennes V, Bergson et la politique: de Jaurès à aujourd'hui. Paris: Presses Universitaires de France, 311-33.

Deleuze, Gilles. (1966), Le bergsonisme. Paris: Presses Universitaires de France (1994).

François, Arnaud. (2008), Bergson, Schopenhauer, Nietzsche. Volonté et réalité. Paris: Presses Universitaires de France.

Jankelevitch, Vladimir. (1959), Henri Bergson. Paris: Presses Universitaires de France (1999).

Riquier, Camille. (2009), Archéologie de Bergson. Temps et métaphysique. Paris: Presses Universitaires de France.

Worms, Frédéric. (2004), Bergson ou les deux sens de la vie. Paris: Presses Universitaires de France. 